\title{
Mercury emission from crematories in Japan
}

\author{
M. Takaoka ${ }^{1}$, K. Oshita ${ }^{1}$, N. Takeda ${ }^{2}$, and S. Morisawa ${ }^{1}$ \\ ${ }^{1}$ Department of Urban and Environmental Engineering, Graduate School of Engineering, Kyoto University, Nishikyo-ku, \\ Kyoto, 615-8540, Japan \\ ${ }^{2}$ Eco-technology Research Center, Ristumeikan University, 1-1-1 Nojihigashi, Kusatsu, Shiga, 525-8577, Japan
}

Received: 30 September 2009 - Published in Atmos. Chem. Phys. Discuss.: 16 December 2009

Revised: 8 April 2010 - Accepted: 8 April 2010 - Published: 20 April 2010

\begin{abstract}
Anthropogenic sources of mercury emissions have a significant impact on global pollution. Therefore, finding uncharacterised sources and assessing the emissions from these sources are important. However, limited data are available worldwide on mercury emissions from crematories. In Japan, $99.9 \%$ of dead bodies are cremated, which is the highest percentage in the world, and more than 1600 crematories are in operation. We thus focused on emissions from crematories in Japan. The number of targeted facilities was seven, and we used continuous emission monitoring to measure the mercury concentrations and investigate mercury behaviour. The total mercury concentrations in stack gases were a few $\mu \mathrm{g} / \mathrm{Nm}^{3}$ (normal cubic meters). Considering the time profile of mercury and its species in cremations, the findings confirmed that the mercury in stack gas originated from dental amalgam. The amount of mercury emissions was calculated using the total concentration and gas flow rate. Furthermore, the annual amount of mercury emission from crematories in Japan was estimated by using the total number of corpses. The emission amount was considerably lower than that estimated in the United Kingdom. From statistical analyses on population demographics and measurements, future total emissions from crematories were also predicted. As a result, the amount of mercury emitted by crematories will likely increase by 2.6-fold from 2007 to 2037.
\end{abstract}

\section{Introduction}

Given in its high volatility, mercury is emitted into the atmosphere from both anthropogenic and natural sources. Subsequently, it enters oceans, lakes, and rivers from the atmosphere directly or from deposits in surrounding basins, even when no specific source of the element is present (Fitzger-

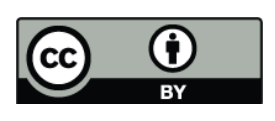

Correspondence to: M. Takaoka (takaoka@environ.mbox.media.kyotou.ac.jp) ald et al., 1998). Some of the inorganic mercury in water is converted into organic mercury, which can be very toxic and is subject to biological accumulation. Consequently, the emission of mercury is of great concern. The United Nations Environment Programme (UNEP) is conducting studies with the goal of a worldwide reduction in mercury (UNEP Chemicals, 2002). These programmes require estimates of the national emissions of mercury from major sources in each country. A report by the Arctic Monitoring and Assessment Programme and UNEP Chemicals (2008), lists mercury emissions from crematories because dental amalgam contains a significant amount of mercury.

According to the Ministry of Health, Labour and Welfare (MHLW) of Japan (2008a), 99.9\% of all bodies (1 108334) were cremated in about 1600 facilities in 2007; this percentage is the highest in the world. With demographic changes, the number of deaths is increasing, and the number of cremations will also increase (MHLW, 2008b). For religious reasons, mercury emissions from crematories in Japan are not regulated by the Air Pollution Control Act or the Waste Management and Public Cleansing Act. However, examining mercury emissions from crematories is needed to determine their environmental impact and to take measures to reduce or monitor them if necessary. Anthropogenic sources of mercury emissions have a significant impact on global pollution. Therefore, finding uncharacterised sources and evaluating the emissions from them are important. However, only limited data on mercury emissions from crematories are available in the literature. According to the Department for Environment, Food and Rural Affairs (DEFRA) in the United Kingdom (2004), mercury emissions in 2020 will be 1.67 times those in 1995 and will peak in 2035. It will contribute $11-35 \%$ of the total mercury emissions in the United Kingdom in 2020. In Sweden, it was estimated to be the third highest contributor of all anthropogenic sources of mercury (Hogland, 1994). Emissions from crematories are also very likely to have a significant impact in Japan.

Published by Copernicus Publications on behalf of the European Geosciences Union. 


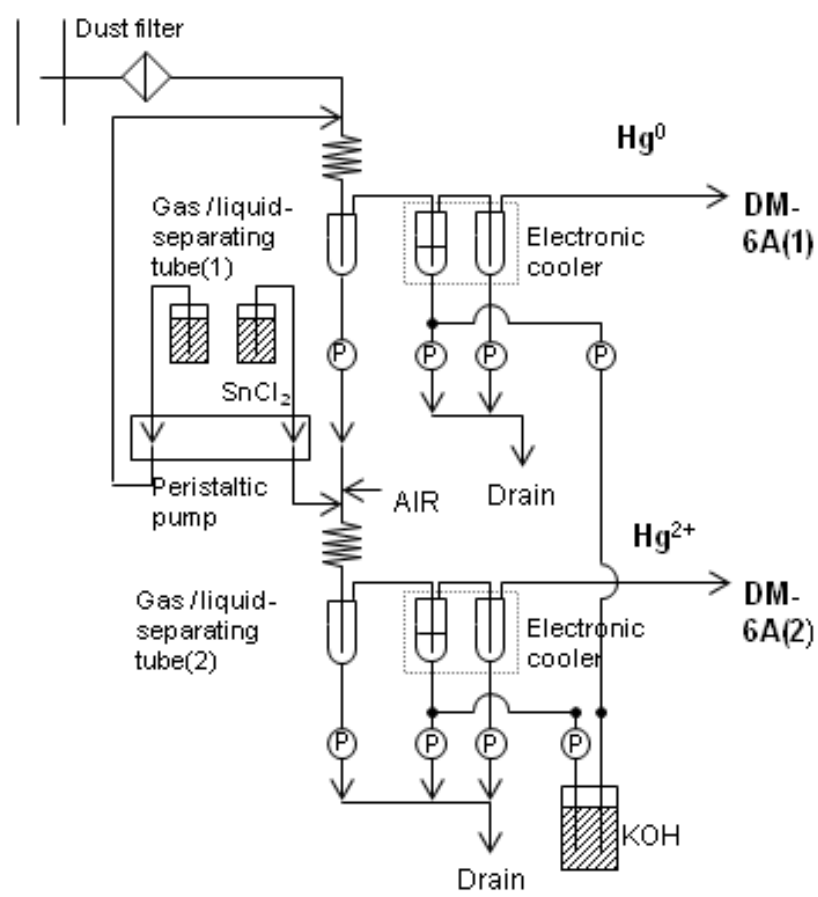

Fig. 1. The pretreatment section of the speciation CEM.

The purposes of this research were to measure actual emission levels, estimate emissions from crematories in Japan using measurement data and clarify the behaviour of mercury in crematory flue gas with the goal of predicting the environmental fate of the mercury in the surrounding area. Finally, future trends in emissions were estimated.

\section{Materials and methods}

\subsection{Facilities}

Table 1 shows the configuration of the seven crematories and the sampling conditions. In Japan, to prevent dioxin emissions from crematories, a guideline was implemented in 2000 requiring installation of air pollution control devices (APCDs) in newly constructed facilities. Although the removal efficiency of mercury by APCDs is beyond the scope of this research, APCDs do have a significant impact on the mercury concentration in final flue gas. Thus, we selected three crematories (Facilities No. 1, 2, and 3) that were constructed after 2000. In these particular facilities, bag filters were used as dust collectors and advanced APCDs had been installed. Additionally, Facility No. 7 also has a bag filter system, although it was constructed in 1998. Conversely, Facilities No. 5 and 6 were not equipped with even a dust collector. All crematories had a series of one secondary combustion chamber to one main combustion chamber, and in all cases, flue gases were cooled by air ejectors. Facility No. 1 used a heat exchanger for flue gas cooling. Natural gas and oil were used as auxiliary fuel in four (Facilities No. 1, 2, 4 , and 7) and three (Facilities No. 3, 5, and 6) of the crematories, respectively.

The origin of the mercury is believed to be dental amalgam (Mills, 1990). Since there is a large difference in mercury emissions between a body with or without mercury amalgam, we conducted many measurements at two facilities (No. 6 and 7) to determine an accurate average mercury concentration. In other crematories, flue gas was sampled twice for each crematory. Since bodies are cremated individually, flue gas was sampled throughout a cremation, from ignition of the secondary burner to extinction of the main burner.

\subsection{Mercury emission monitoring}

Knowing the species of mercury in stack gas will contribute to a better understanding of the environmental fate of mercury. The mercury concentrations in stack gas were monitored continuously using a speciation mercury continuous emission monitor (CEM, MS1A+DM-6A; Nippon Instruments). This device was developed by Nippon Instruments and the Central Research Institute of the Electric Power Industry in Japan (Chua et al., 2003). The pretreatment section of the speciation CEM is shown in Fig. 1.

An aqueous solution of $1 \mathrm{~mol} / \mathrm{L}$ potassium chloride and flue gases that had been passed through the dust filter is mixed with a gas/liquid contact coil to transfer oxidised mercury $\left(\mathrm{Hg}^{2+}\right)$ into the liquid phase. The gas flow rate is $0.5 \mathrm{~L} / \mathrm{min}$, and the gas and solution are separated in the gas/liquid separating tube. Elemental mercury $\left(\mathrm{Hg}^{0}\right)$ in the gas phase is washed with $1 \mathrm{~mol} / \mathrm{L}$ potassium hydroxide to remove any acid gas, and the excess moisture in the gas is condensed with an electric cooler. Then, the gas including $\mathrm{Hg}^{0}$ is fed into the first detection device, which is an atomic absorption mercury analyser (DM-6A(1)). The aqueous solution in the gas/liquid separating tube is directed into another gas/liquid contact coil and then mixed with $1 \%$ stannous chloride and $10 \%$ sulphuric acid. In this process, the $\mathrm{Hg}^{2+}$ in solution is reduced, liberating gaseous $\mathrm{Hg}^{0}$, which passes through another gas/liquid separating tube before it is fed into the second detection device (DM-6A(2)) to quantify the $\mathrm{Hg}^{2+}$. Here, the gas flow rate must be the identical to that in line DM-6A(1).

Given this speciation, CEM was developed based on the Ontario Hydro method, which is used to determine the elemental, oxidised, particle-bound and total mercury emissions from coal-fired stationary sources (ASTM D6784-02, 2008); it was compared with the Ontario Hydro method periodically and showed an excellent correlation for mercury concentrations ranging from 0 to $100 \mu \mathrm{g} / \mathrm{Nm}^{3}$ in a municipal solid waste incinerator (Chua et al., 2003). The detection limit of this device is $0.1 \mu \mathrm{g} / \mathrm{Nm}^{3}$.

Some flue gas obtained at Facility No. 7 was simultaneously sampled using an absorption method based on Japanese Industrial standard K0222. Flue gas was passed through 
Table 1. The configurations and mercury concentration of seven crematories.

\begin{tabular}{|c|c|c|c|c|c|c|c|c|c|c|c|c|}
\hline Facility No. & \multicolumn{2}{|l|}{1} & \multicolumn{2}{|l|}{2} & \multicolumn{2}{|l|}{3} & \multicolumn{2}{|l|}{4} & \multicolumn{2}{|l|}{5} & 6 & 7 \\
\hline Dust collector & \multicolumn{2}{|c|}{ Bag filter } & \multicolumn{2}{|c|}{ Bag filter } & \multicolumn{2}{|c|}{ Bag filter } & \multicolumn{2}{|c|}{$\begin{array}{l}\text { Electrostatic } \\
\text { precipitator }\end{array}$} & \multicolumn{2}{|l|}{-} & - & Bag filter \\
\hline Advanced APCD & \multicolumn{2}{|c|}{$\begin{array}{l}\text { Catalytic } \\
\text { reactor }\end{array}$} & \multicolumn{2}{|c|}{$\begin{array}{l}\text { Catalytic } \\
\text { reactor }\end{array}$} & \multicolumn{2}{|c|}{$\begin{array}{l}\text { Activated carbon } \\
\text { filter }\end{array}$} & \multicolumn{2}{|l|}{-} & \multicolumn{2}{|l|}{-} & - & - \\
\hline Flue gas cooling device & \multicolumn{2}{|c|}{$\begin{array}{l}\text { Heat exchanger } \\
\text { +air ejecor }\end{array}$} & \multicolumn{2}{|c|}{ Air ejector } & \multicolumn{2}{|c|}{ Air ejector } & \multicolumn{2}{|c|}{ Air ejector } & \multicolumn{2}{|c|}{ Air ejector } & Air ejector & Air ejector \\
\hline Ventilation & \multicolumn{2}{|c|}{ Induced } & \multicolumn{2}{|c|}{ Induced } & \multicolumn{2}{|c|}{ Induced } & \multicolumn{2}{|c|}{ Induced } & \multicolumn{2}{|c|}{ Induced } & Induced & Induced \\
\hline $\begin{array}{l}\text { The number of secondary } \\
\text { chambers connected to } \\
\text { flue gas treatment line }\end{array}$ & \multicolumn{2}{|l|}{2} & \multicolumn{2}{|l|}{2} & \multicolumn{2}{|l|}{2} & \multicolumn{2}{|l|}{3} & \multicolumn{2}{|l|}{2} & 1 & 2 \\
\hline Fuel & \multicolumn{2}{|c|}{ Natural gas } & \multicolumn{2}{|c|}{ Natural gas } & \multicolumn{2}{|c|}{ Kerosene } & \multicolumn{2}{|c|}{ Natural gas } & \multicolumn{2}{|c|}{ Kerosene } & Kerosene & Natural gas \\
\hline Experimental No. & 1 & 2 & 1 & 2 & 1 & 2 & 1 & 2 & 1 & 2 & 44 & 33 \\
\hline Cremation time & 58 & 57 & 66 & 59 & 48 & 68 & 64 & 45 & 71 & 66 & $84(60-107)$ & $57(47-75)$ \\
\hline Age & 64 & 75 & 91 & 79 & 98 & 85 & 66 & 80 & 84 & 65 & $81(52-99)$ & $77(29-101)$ \\
\hline Sex & female & female & female & female & female & female & male & female & female & male & $\begin{array}{l}\text { male(24), } \\
\text { female(20) }\end{array}$ & $\begin{array}{l}\text { male(22), } \\
\text { female(11) }\end{array}$ \\
\hline $\begin{array}{l}\text { Hg concentraion } \\
\left(\mu \mathrm{g} / \mathrm{Nm}^{3}\right)\end{array}$ & 0.2 & 0.9 & 0.3 & 0.4 & 0.4 & 3 & 30.3 & 1.4 & 2.8 & 0.3 & $3.0(0.2-82.7)$ & $4.3(0.8-25.2)$ \\
\hline $\begin{array}{l}\mathrm{Hg}^{0} \text { concentraion } \\
\left(\mu \mathrm{g} / \mathrm{Nm}^{3}\right)\end{array}$ & 0.1 & 0.5 & 0.2 & 0.1 & 0.3 & 2.7 & 30.1 & 1.3 & 2.7 & 0.2 & $2.6(0.1-81.2)$ & $2.2(0.0-23.6)$ \\
\hline $\begin{array}{l}\mathrm{Hg}^{2+} \text { concentraion } \\
\left(\mu \mathrm{g} / \mathrm{Nm}^{3}\right)\end{array}$ & 0.1 & 0.4 & 0.1 & 0.3 & 0.1 & 0.3 & 0.3 & 0.1 & 0.1 & 0.1 & $0.5(0.1-2.7)$ & $2.1(0.7-8.1)$ \\
\hline
\end{tabular}

a glass filter and bubbled through a sulphuric acid solution with potassium permanganate $\left(\mathrm{KMnO}_{4}\right)$. Mercury absorbed in the solution was measured using a frameless reduction vapourisation atomic absorption mercury analyser (RA-2; Nippon Instruments). The sulphuric acid solution with $\mathrm{KMnO}_{4}$ oxidises organic or inorganic mercury into bivalent mercury ions, and using stannous chloride as a reducing agent, bubbling changes ions into mercury vapour. This mercury vapour is then directed to an absorption cell and atomic absorption was measured at a wavelength of $253.7 \mathrm{~nm}$ to determine the quantity of mercury.

Carbon monoxide $(\mathrm{CO})$, oxygen $\left(\mathrm{O}_{2}\right)$, carbon dioxide $\left(\mathrm{CO}_{2}\right)$, nitrogen oxide $\left(\mathrm{NO}_{\mathrm{x}}\right)$, and sulphur dioxide $\left(\mathrm{SO}_{2}\right)$ concentrations were also monitored using continuous emission monitors (CGT-7000 for CO, NOA-7000 for $\mathrm{O}_{2}$ and $\mathrm{NO}_{\mathrm{x}}$, SOA-7000 for $\mathrm{SO}_{2}$; Shimadzu Co. Ltd.). In crematory No. 7, the $\mathrm{HCl}$ concentration was measured manually based on Japanese Industrial Standard K0107.

\section{Results and discussion}

\subsection{Mercury concentration in crematory flue gas}

First, we show the relationship between the JIS and CEM methods in Fig. 2. As a result, the regression equation is as follows:

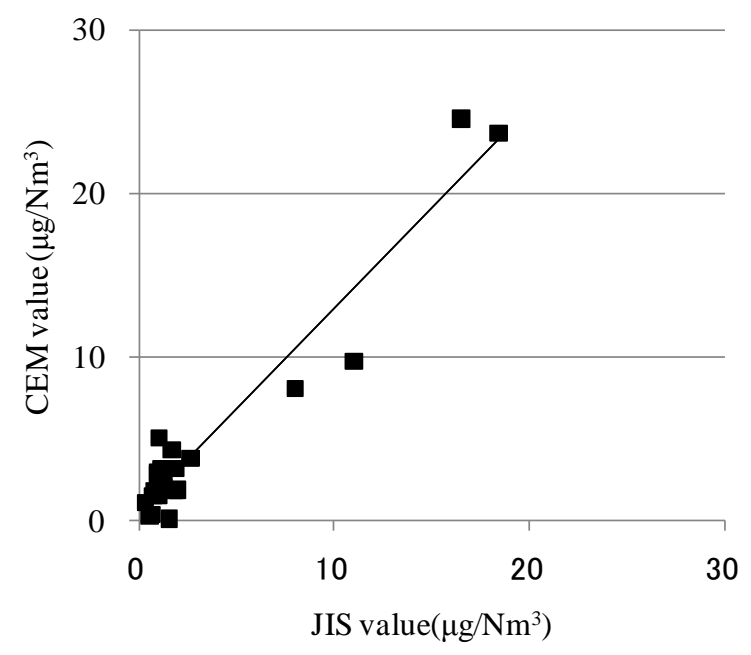

Fig. 2. The relationship between the JIS and CEM methods.

$\mathrm{CEM}=1.23(\mathrm{JIS})+0.687\left(R^{2}=0.93\right)$,

where $\mathrm{CEM}=\mathrm{CEM}$ value $\left(\mu \mathrm{g} / \mathrm{Nm}^{3}\right) ; \mathrm{JIS}=\mathrm{JIS}$ value $\left(\mu \mathrm{g} / \mathrm{Nm}^{3}\right)$.

Although the CEM values were slightly higher than the JIS values, the correlation coefficient was considered to be sufficiently high to determine trends in mercury emissions. 


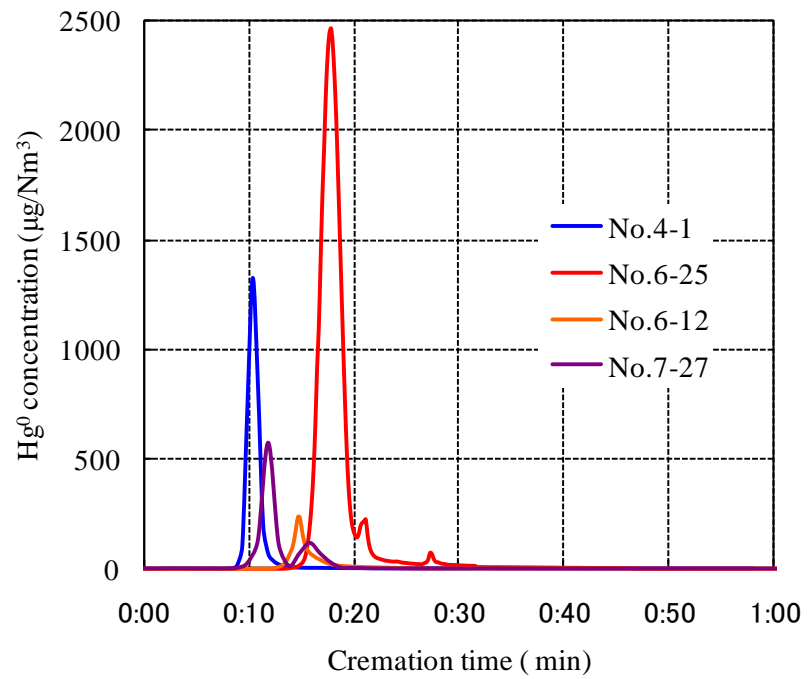

Fig. 3. Temporal changes in the elemental mercury $\left(\mathrm{Hg}^{0}\right)$ concentration in crematory flue gas.

When using the CEM value, we may need to be aware of some degree of overestimation.

The total averaged mercury concentration in stack gas was $3.6 \mu \mathrm{g} / \mathrm{Nm}^{3}$, which consisted of $\mathrm{Hg}^{0}\left(2.6 \mu \mathrm{g} / \mathrm{Nm}^{3}\right)$ and $\mathrm{Hg}^{2+}\left(1.1 \mu \mathrm{g} / \mathrm{Nm}^{3}\right)$. $\mathrm{Hg}$ concentrations ranged from 0.2 to $82.7 \mu \mathrm{g} / \mathrm{Nm}^{3}$. When the concentration was normalised by $12 \% \mathrm{O}_{2}$ to compare the concentration to municipal solid waste incinerator flue gas, the total averaged mercury concentration was $17.8 \mu \mathrm{g} / \mathrm{Nm}^{3}$, which was higher than that in stack gas of a municipal solid waste incinerator (Takaoka et al., 2002). This is because the $\mathrm{O}_{2}$ concentration is so high (15.8-20.8\%) that the concentration normalised by $12 \% \mathrm{O}_{2}$ becomes high. The mercury concentrations for the facilities are shown in Table 1 . The average mercury concentration by facility ranged from 0.4 to $15.9 \mu \mathrm{g} / \mathrm{Nm}^{3}$. This difference is not caused by the structure of each crematory, including APCDs, but depends on whether the body contains mercury amalgam.

Mercury concentrations in 22 crematory flue gas samples at three crematories, $\mathrm{A}, \mathrm{B}$, and $\mathrm{C}$, were measured in the United Kingdom (Edwards, 2001). According to the reports, the average mercury concentrations normalised by $11 \% \mathrm{O}_{2}$ were 690,880 and $430 \mu \mathrm{g} / \mathrm{Nm}^{3}$ at crematory A, B and C, respectively. The mercury concentration in flue gas is influenced by the volume of exhaust gas per cremation. The average flue gas volume varied considerably by crematory; indeed, the range was $3250-14600 \mathrm{Nm}^{3} / \mathrm{h}$. The average volume of exhaust gas in a cremation in Japan is 3-10 times larger than that in the United Kingdom because the flue gas was cooled by air dilution using an air ejector in Japan. However, this means that the mercury concentration in the UK exhaust gas is very high by comparison. Hogland (1994) reported the mercury concentration from a crematory in Lund,
Sweden. Although the volume of exhaust gas was about 1/5$1 / 20$ of that in Japan, the maximum concentration achieved was $60000 \mu \mathrm{g} / \mathrm{Nm}^{3}$, which is extremely high. From comparisons with data for other countries, we suggest that the average mercury quantity emitted in Japan is low.

The contribution of $\mathrm{Hg}^{0}$ to the total mercury was $70 \%$, which is relatively high. $\mathrm{Hg}^{0}$ concentrations ranged from 0.1 to $81.2 \mu \mathrm{g} / \mathrm{Nm}^{3}$, whereas $\mathrm{Hg}^{2+}$ concentrations ranged from 0.1 to $8.1 \mu \mathrm{g} / \mathrm{Nm}^{3}$. A higher peak was observed only in $\mathrm{Hg}^{0}$.

The chemical form of mercury in flue gas is known to be influenced by the gas composition, especially the presence of halogen compounds (Takaoka, 2005). HCl was measured in Facility No. 7, and its concentration was found to range from 2 to $13 \mathrm{mg} / \mathrm{Nm}^{3}$. Even when the $\mathrm{HCl}$ was removed by a bag filter (this facility did not use alkaline reagents for acid gas removal), the concentration was very low compared with that in the municipal solid waste incinerator. To check the validity of the mercury form from the viewpoint of thermodynamics, the stable form of mercury was calculated under the following conditions: $19.6 \% \mathrm{O}_{2}, 10 \mathrm{ppm} \mathrm{HCl}$ and $4 \%$ $\mathrm{H}_{2} \mathrm{O}$ using Fact sage 5.0. As a result, $\mathrm{HgCl}_{2}$ was found to be stable at $200^{\circ} \mathrm{C}$ and $\mathrm{Hg}^{0}$ to be dominant at temperatures above $600{ }^{\circ} \mathrm{C}$. Because $\mathrm{Hg}^{0}$ was dominant in flue gas based on measurement results, there was a difference in the chemical form between the results of thermodynamics and measurements. It might be cleared by measurement in upstream flue gas before bag filter.

\subsection{Temporal change in mercury concentration}

Two patterns in changes of mercury concentrations were observed. The first pattern is shown in Fig. 3. In some samples, a large peak in $\mathrm{Hg}^{0}$ appeared at $10-20 \mathrm{~min}$; two samples exceeded $1000 \mu \mathrm{g} / \mathrm{Nm}^{3}$. This period indicates the burning of the cephalic part of the corpse. Considering the behaviour of mercury in cremations, the findings confirmed that the mercury in stack gas originated from the mercury in dental amalgam. This behaviour was previously reported by Hogland (1994). During this period, peaks were observed in 36 samples.

In the other pattern, no distinct peak of $\mathrm{Hg}^{0}$ was detected in the remaining 51 samples. In some samples, a small peak of $\mathrm{Hg}^{2+}$ was noted. Various internal organs of the human body contain mercury, and the mercury quantity in an adult is estimated to be more than $3.3 \mathrm{mg} /$ body, apart from dental amalgam (The Chemical Society of Japan, 1977). Moreover, the mercury contents of liver $(0.71 \mathrm{mg})$ and kidney $(0.28 \mathrm{mg})$ are reportedly quite high. If these organs are burned in a short time, calculations indicate that a small peak (about 1$3 \mu \mathrm{g} / \mathrm{Nm}^{3}$ ) may appear. From comparisons of the measurements and the above calculations, we can conclude that mercury in dental amalgam has a significant impact on mercury emissions from crematories. 


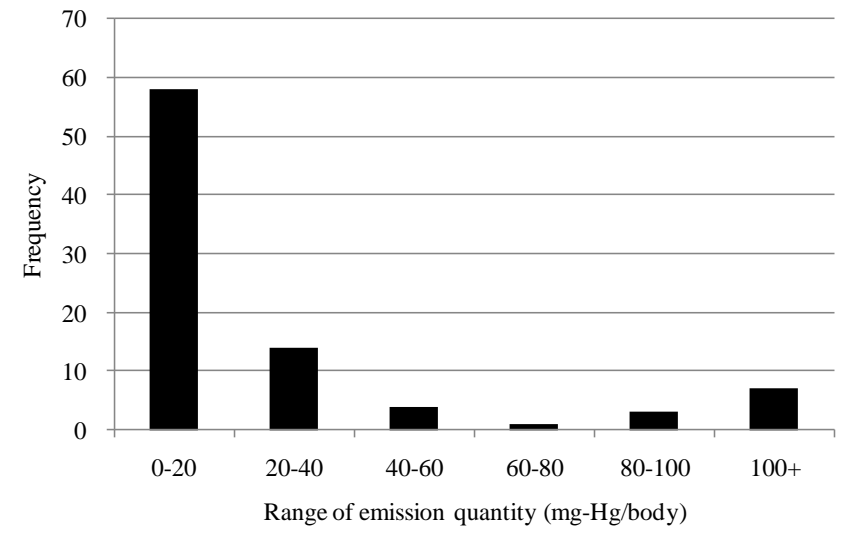

Fig. 4. The distribution of emission quantities calculated using measured data.

\subsection{Mercury emission from crematories}

Total emissions from all active crematories in Japan were estimated using the following equations:

Total emissions $(\mathrm{mg} /$ year $)=$ Emission quantity $(\mathrm{mg} /$ body $)$ $x$ the number of cremations (bodies/year)

Emission quantity (mg/body)

$=$ Mercury concentration $\left(\mathrm{mg} / \mathrm{Nm}^{3}\right)$

$\times$ dry gas volume $\left(\mathrm{Nm}^{3} / \mathrm{h}\right)$

$x$ cremation period $(\mathrm{h}) /$ the number of cremations (bodies)

The amount of mercury emission was calculated to be $31.7 \mathrm{mg} /$ cremation using the total concentration and gas flow rate. The standard deviation was $64 \mathrm{mg} /$ body; this was so large because the mercury quantity per body has a large range from 0.7 to $362 \mathrm{mg} /$ body. In the United Kingdom, $150 \mathrm{mg} /$ four cremations was proposed as a regulatory criterion by DEFRA (2004). Taking this to be equivalent to $37.5 \mathrm{mg} /$ body, the values in 15 samples in this research were over this level.

The distribution of emission quantities calculated using measured data is shown in Fig. 4. As the emission quantity increases, the frequency decreases. However, the frequency increased at over $80 \mathrm{mg} /$ body. In the United Kingdom, in total, 54 cremations were tested at two separate locations (Rahill, 2008). From the results, 31 cremations were suspected to have been of bodies with no amalgam fillings. Average mercury release per cremation over 54 cremations was reported to be $240 \mathrm{mg} /$ body. The United States Environmental Protection Agency (US EPA) also reported that the emission quantity was $456 \mathrm{mg} /$ body from nine cremations (Rahill,

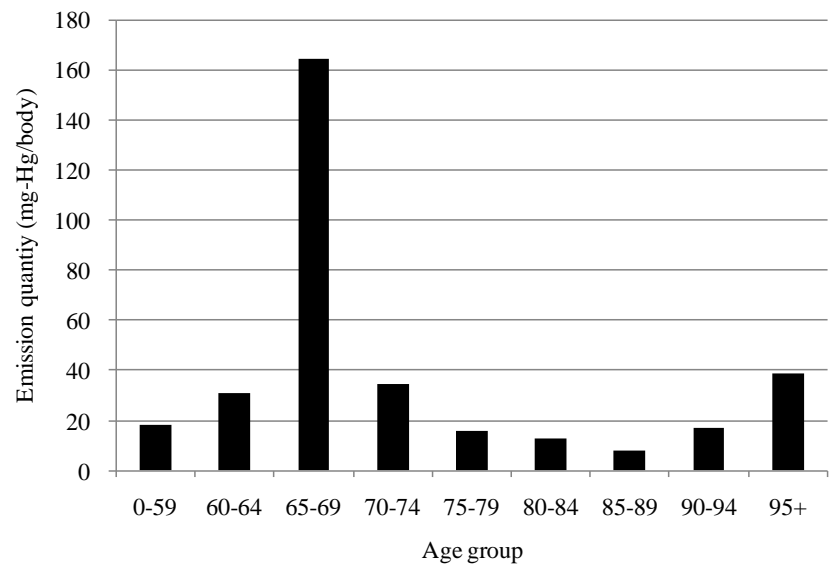

Fig. 5. The amount of mercury emission per cremation calculated using measured data by age group (number of samples by age group: 0-59:4, 60-64:6, 65-69:7, 70-74:9, 75-79:15, 80-84:17, 85-89:9, 90-94:12, 95+:8).

2008). Although $0.94 \mathrm{mg} /$ body was reported in another US EPA document, this value would have been for bodies with no amalgam filling (US EPA, 1997). According to the UNEP tool kit for the identification and quantification of mercury releases (2005), the emission quantity in various countries ranged from 0.1 to $5.1 \mathrm{~g} / \mathrm{body}$. Comparing our results with these reported data, including corpses with amalgam fillings, the emission quantity obtained in this research is quite low. The use of amalgam has a close relationship with mercury emissions. The amount of mercury in amalgam in one filling was reported to be $600 \mathrm{mg}$ by Mills (1990). We sought to examine the actual mercury content in one used amalgam filling. According to our ongoing research, the weight per filling removed by a dentist ranged from 56 to $231 \mathrm{mg}$. The mercury content in an amalgam filing ranged from 42.5 to $53.0 \%$. Therefore, the average amount of mercury per filling was $51.6 \mathrm{mg}$. This is at least one of the reasons why emissions in Japan are low.

The amount of mercury emission per cremation calculated using measured data by age group is shown in Fig. 5. The maximum value was obtained in the age range 65-69 years. The second highest value was observed in the age ranges of $95+, 70-74$, and 60-64 years. In addition, a difference in mercury emission was observed between males and females. This trend is consistent with a report from the United Kingdom (Edwards, 2001).

These mean values $(31.7 \mathrm{mg} /$ body $)$ were multiplied by 1169174 , the number of bodies cremated in 2007, which was calculated using the number of corpses (1 108334 including dead bodies of uncertain age (MHLW, 2008b)) and the cremation rate $(99.9 \%)$; total emissions were estimated to be $35.1 \mathrm{~kg} /$ year. Considering the number of bodies and the emission quantity by age group, the total estimated emissions decreased slightly to $32.5 \mathrm{~kg} / \mathrm{year}$. This constitutes less 


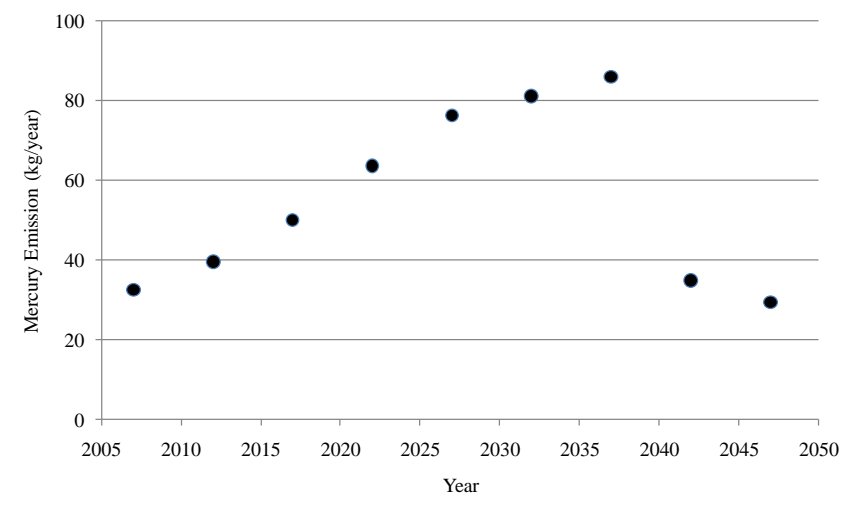

Fig. 6. Estimated future trends of total mercury emissions in Japan from crematories based on population demographic statistics and measured data.

than $0.01 \%$ of the total amount of mercury released into the atmosphere (21-28 tons/year) in Japan (Kida et al., 2008).

To estimate mercury emissions in the United Kingdom, $3 \mathrm{~g} /$ body was used as the emission quantity (DEFRA, 2004). This value is based on Mills' report (1990), which assumes that a dead body has five restored teeth with amalgam fillings containing $0.6 \mathrm{~g}$ mercury. Based on this assumption, the mercury emission was calculated to be $3300 \mathrm{~kg} / \mathrm{year}$ in Japan. This procedure leads to an obvious overestimation. The mercury release to the air from crematories should be based on measurements.

Next, total future trends in emission were calculated using statistics on population demographics (NIPSSR, 2008) and the emission quantity obtained in this research. That is, the emission quantity was multiplied by the number of dead bodies by age group. Here, we assume that the emission quantity obtained in this research is a property of each group and shifted it to the emission quantity of the next age range as 5 years passed. We set the cremation rate to be $100 \%$. As a result, estimated future trends of total mercury emissions from crematories based on the statistics of population demographics and measured data are shown in Fig. 6. The amount of mercury emissions from crematories is expected to increase to $86 \mathrm{~kg} /$ year, about 2.6-fold, between 2007 and 2037. The distinct distribution of emission quantities is expected to show a rapid decrease in 2042 because the highest emission quantity ( $164 \mathrm{mg} /$ body) moved outside the age ranges. In fact, the distribution of emission quantities would then be expected to moderate and then decline because of the impact of dental care, such as the removal of amalgam fillings, the loss of teeth and loss of mercury in amalgam fillings (Skare, 1995) as the age group shifts. Although we should use measurement data to estimate current emissions, we can combine measurement data with demographic statistics on dental care or material flow data of mercury amalgam to estimate accurate future trends in mercury emissions from crematories.

\section{Conclusions}

In this study, to measure the actual emission level and estimate the emission from crematories in Japan using measurement data, the mercury concentration in crematory flue gas from mercury emissions was examined at seven facilities. Total averaged mercury concentration in stack gas was $3.6 \mu \mathrm{g} / \mathrm{Nm}^{3}$, which consisted of $\mathrm{Hg}^{0}$ at $2.6 \mu \mathrm{g} / \mathrm{Nm}^{3}$ and $\mathrm{Hg}^{2+}$ at $1.1 \mu \mathrm{g} / \mathrm{Nm}^{3}$. The mercury concentration ranged from 0.2 to $82.7 \mu \mathrm{g} / \mathrm{Nm}^{3}$. At two facilities, we used continuous emission monitoring to measure mercury concentrations and to evaluate mercury behaviour. In some samples, a large peak of $\mathrm{Hg}^{0}$ appeared at $10-20 \mathrm{~min}$. Considering the behaviour of mercury in cremations, the findings confirmed that mercury in stack gas originated from dental amalgam. The amount of mercury emitted was calculated to be $31.7 \mathrm{mg} /$ cremation using the total concentration and gas flow rate. The emission quantity obtained in this research is apparently quite low. Although the reason for this is unclear, the mercury amount per filling in the Japanese oral cavity may be smaller than that in other countries. Furthermore, the annual amount of mercury emission from crematories in Japan was estimated using the total number of corpses. The total emissions were estimated to be $35.1 \mathrm{~kg} /$ year. Total future trends in emissions were calculated using demographic statistics and the emission quantity obtained in this research. As a result, the amount of mercury emissions from crematories is expected to increase by 2.6-fold between 2007 and 2037.

One possible countermeasure would be to remove amalgam fillings before cremation, but this may be difficult to actualize for practical and religious reasons.

Acknowledgements. We are grateful for financial support in the form of a Grant-in-Aid for Waste Treatment Research and Health Sciences Research Grants in FY 2007 to 2009 from the Japanese government and for cooperation with the sampling and mercury analysis from each municipality, and Shoji Eguchi of Taiyo Chikuro Industries and Koji Tanida of Nippon Instruments.

Edited by: R. Ebinghaus

\section{References}

Arctic Monitoring and Assessment Programme (AMAP) and UNEP Chemicals: Technical Background Report to the Global Atmospheric Mercury Assessment, online available at http://www.chem.unep.ch/mercury/Atmospheric_Emissions/ Atmospheric_emissions_mercury.htm, 2008.

ASTM D6784-02: Standard test method for elemental, oxidized, particle-bound and total mercury in flue gas generated from coalfired stationary sources (Ontario Hydro Method), 2008.

Chua, A., Tanida, K., Takaoka, M., and Noda, N.: Development of mercury CEMs for emission gases. Proc. of 18th International Low-Rank Fuels Symposium, 1-9, 2003.

Department for Environment Food and Rural Affairs(DEFRA), UK; Mercury emissions from crematoria Second consultation, De- 
partment for Environment, Food and Rural Affairs; Welsh Assembly Government; Scottish Executive Environment and Rural Affairs Dept. Available at: http://www.defra.gov.uk/corporate/ consult/crematoria-two/consultation.pdf, 2004.

Edwards, P.: Reviews of Emissions from Crematoria in the UK Volume A- Emissions, Measurements, AEA Technology Report, Resurgam, 44, 81-128 and Pharos International, 67(3), 1-19, 2001.

Fitzgerald, W. F., Engstrom, D. R., Mason, R. P., and Nater, E. A.: The case for atmospheric mercury contamination in remote areas, Environ. Sci. Technol., 32, 1-7, 1998.

Hogland, W.: Usefulness of selenium for the reduction of mercury emissions from crematoria, J. Environ. Qual., 23, 1364-1366, 1994.

Kida, A., Sakai, S., Takaoka, M., Hirai, Y., Moritomi, H., and Yasuda, K.: Study on air emission inventory of mercury including waste management processes and emission reduction measures (K1940), 2008 (in Japanese).

Mills, A.: Mercury and crematorium chimneys, Nature, 346, p. 615, 1990.

Rahill, P.: Mercury Emissions and the Cremation Process-2008, Available at: http://www.matthewscremation.com/pdf/Mercury Emissions_\&_Crem_Process.pdf, 2008.

Skare, I.: Mass balance and systemic uptake of mercury released from dental amalgam fillings, Water, Air and Soil Pollution, 80, 59-67, 1995.
Takaoka, M., Takeda, N., Fujiwara, T., Kurata, M., and Kimura, T.: Control of mercury emission from a municipal solid waste incinerator in Japan, J. Air Waste Manag. Assoc., 52, 931-940, 2002.

Takaoka, M.: Behavior and control of mercury in the waste combustion process, Waste Manage. Res., 16, 213-222, 2005 (in Japanese)

The Chemical Society of Japan (Eds): Mercury, Maruzen Co., Ltd., Tokyo, Japan, 1977 (in Japanese).

The Ministry of Health, Labour and Welfare (MHLW), Public Health Administration Report, online availabe at http: //www.e-stat.go.jp/SG1/estat/List.do?lid=000001035603, 2008a (in Japanese).

The Ministry of Health, Labour and Welfare (MHLW), Vital Statistics, online available at http://www.mhlw.go.jp/toukei/saikin/hw/ jinkou/suikei08/index.html, 2008b (in Japanese).

UNEP Chemicals: Global Mercury Assessment, online available at http://www.chem.unep.ch/mercury/report/gma-report-toc.htm, 2002.

UNEP Chemicals: Tool kit for the identification and quantification of mercury releases, online available at http://www.chem.unep. ch/mercury/Toolkit/default.htm, 2005.

National Institute of Population and Social Security Research (NIPSSR), Statistics of Population Projection, 2008.

US EPA: Mercury Study Report to Congress. US EPA, online available at http://www.epa.gov/mercury/report.htm, December 1997. 